JOURNAL OF RESEARCH

AND

REVIEW

\title{
Detection of Hepatitis B surface Antibodies (Anti-HBs), IN ScIENCE Lifelong Immunity to HBV in HIV positive Patients in Ojo, Lagos, Nigeria
}

\section{AbdulAzeez A. Anjorin ${ }^{1}$, Akeeb O. Bola Oyefolu ${ }^{1}$, Latifat M. Laguda ${ }^{1}$ 'Kabir O. Akinyemi ${ }^{1}$}

${ }^{1}$ Department of Microbiology, Lagos State University, Ojo, Nigeria.

\section{Correspondence}

AbdulAzeez A. Anjorin,

Department of Microbiology, Lagos State University, Ojo PMB.0001 LASU Post Office,

Lagos, Nigeria.

E-mail: abdul-azeez.anjorin@lasu.edu.ng, Telephone number: +234 8020956357

\section{Funding information}

Personal funding.

\begin{abstract}
:
Introduction: Detection of Hepatitis B surface antibodies (anti-HBs) in the serum implies that an individual is immune to HBV infection either from vaccination or past infection, which usually persists for life.

Aims: This study aimed to determine the seropositivity of anti-HBs among HIV-seropositive patients, and further appraise the effect of co-infection on their immunological status in Ojo, Lagos, Nigeria.

Materials and Methods: A total of 74 blood samples collected from HIV positive patients were analysed for anti-HBs (HBsAb) by Immunochromatographic assay (Biotec, UK). CD4+ count was determined using BD FACS Count Automated analyser.

Results: Out of the $74 \mathrm{HIV}$ infected patients screened, $12(16.2 \%)$ males and $62(83.8 \%)$ females, 2 patients $(2.7 \%)$ were positive for anti-HBs, with no prevalence among the males and $2.7 \%$ among the females. AntiHBs was only recorded in HIV positive patients in the 21-30 years age group $(8.7 \%)$. The result showed anti-HBs lifelong protection to HBV among HIV patients with CD4+ Count ranging from 601-700 and 901-1000 to be $1.7 \%$ and $1.7 \%$ respectively. Protection of $3.5 \%$ was reported among antiretroviral therapy (ART) naïve patients and $0 \%$ protection among ART patients.

Conclusion: Our findings showed prevalence of $2.7 \% \mathrm{HBsAb}$ in the studied HIV positive patients with a protection of $3.5 \%$ anti-HBs to HBV among antiretroviral therapy (ART) naïve patients in Ojo, Lagos. The low prevalence of HBsAb in HIV positive patients may be attributed to suppression of immune responses leading to the loss of previously developed protective antibody against HBV infection. We hereby suggest anti-HBs screening for all HIV positive patients and that those negative should be vaccinated to help them develop protective immunity to HBV infection.

To Keywords: HBV, Anti-HBs, HIV, CD4 Count, Lagos.
\end{abstract}

This is an open access article under the terms of the Creative Commons Attribution License, which permits use, distribution and reproduction in any medium, provided the original work is properly cited.

(c) 2018 The Authors. Journal of Research and Reviews in Science - JRRS, A Publication of Lagos State University 


\section{INTRODUCTION}

Viral hepatitis is a systemic disease that mostly affects the liver, with Hepatitis viruses $A-E$ being the causative agents [1]. HBV is blood borne, and the transmission is mostly through exposure to infectious body fluids like urine, semen, sweat, saliva and tears, use of contaminated needles, blood transfusion, vertical transmission which includes mother to child through placenta and infectious birth canal, as well as unprotected sexual contact [2, 3]. There are 2 billion people infected with HBV, with more than 350 million having chronic (HBsAg positive for at least 6 months) infection that results in 500,000 to 1.2 million deaths per year $[4,5]$. Detection of Hepatitis B surface antibodies (Anti-HBs) in the serum implies that an individual is immune to HBV infection either from vaccination or past infection, which usually persists for life [6, 7]. In Nigeria, high HBV prevalence has been reported among surgeons $(25.7 \%)$, voluntary blood donors (23.4\%) and infants $(16.3 \%)$ [8, 9]. Most patients either develop immunity $(87-90 \%)$ and clear the infection or become chronic carriers after infection with HBV. HIV positive individuals become six times more likely to develop chronic HBV, and are more likely to lose previously developed protective anti-HBs antibody and develop acute Hepatitis $B$ infection, a risk also known to affect CD4 count [10].

Human Immunodeficiency Virus (HIV) and Hepatitis B Virus (HBV) are annihilating viruses that share certain epidemiological characteristics such as risk population and transmission routes, placing HIV positive individuals at risk of co-infection with HBV [11]. HIV/HBV co-infection has been observed to cause increased morbidity and mortality as compared to HIV or HBV mono-infections [12]. The seroprevalence of HIV and HBV co-infection ranges from $6.3 \%$ to $39 \%$ $[13,14]$. About $58.1 \%$ of patients with chronic liver disease were reported $\mathrm{HBsAg}$ positive in southern parts of Nigeria [15]. In 2012, a study in Kano, Nigeria reported that among $440 \mathrm{HIV}$ positive patients, $12.3 \%$ were co-positive for HBV [16]. The seropositivity of HBV infection markers among HIV-infected individuals ranges from $4.2 \%$ to $19.4 \%$ for $\mathrm{HBsAg}$, and $22.9 \%$ to $70.4 \%$ for anti-HBc [17]. Only a few centres carry out routine screening for HBV in HIV positive patients in Nigeria, as it is not yet adopted as a national policy by the government. However, most studies on HIV positive patients have dwelled on the prevalence of HBsAg. This study was therefore carried out to determine the seroprevalence of protective immunity to HBV (AntiHBs) in HIV positive patients and to evaluate the effect of co-infection on their immunological status in Ojo, Lagos State, Nigeria.

\section{MATERIAL AND METHODS}

\subsection{Study Design}

This study was a community health centre - based seroepidemiological surveillance of Hepatitis B Surface Antibodies (Anti-Hbs) in HIV positive patients with a further plan to investigate the effect of co-infection of the virus on their immunological status. Designed
Questionnaires were used to collect information on their bio-data including: age, sex and marital status.

\subsection{Study Area and Population}

This study was conducted among outpatients attending Ojo Primary Health Center in Ojo LGA of Lagos State. A total of seventy-four (74) HIV positive confirmed subjects of both sexes, attending Ojo Primary Health Center were enrolled for this study in November, 2015.

\subsection{Sample Collection and Processing}

Five millilitre of blood was collected by venipuncture and transported to the Central Research Laboratory, Department of Microbiology, Lagos State University, Ojo. The blood samples were immediately centrifuged at $4000 \mathrm{rpm}$ for $5 \mathrm{mins}$ to ensure that clear sera were obtained. They were pipetted into cryogenic vials and stored away in $-30^{\circ} \mathrm{C}$ freezer until further processing.

\subsubsection{HIV Test}

HIV-1/2 antibodies were detected in the sera of the patients using two different Immunochromatographic capillary assays. HIV antibodies were first detected with the Determine ${ }^{\mathrm{TM}} \mathrm{HIV}-1 / 2$ kit (Alere Medical, Japan). Alere Determine ${ }^{\mathrm{TM}} \mathrm{HIV}-1 / 2$ is a visual read, qualitative immunoassay for the detection of antibodies to HIV-1 and HIV-2. All samples reactive to the Determine kit were further tested using the Uni-Gold ${ }^{\mathrm{TM}}$ HIV test kit (Trinity Biotech, Ireland) for confirmation of the presence of antibodies to HIV. Uni-Gold ${ }^{\mathrm{TM}} \mathrm{HIV}$ is a single use immunoassay for the rapid detection of antibodies to HIV-1 and HIV-2. Only samples reactive to both Determine and Uni-Gold were considered HIVpositive. All procedures were carried out according to the manufacturers' instruction. The serum samples which were found to be HIV positive were labelled and stored at $-30^{\circ} \mathrm{C}$ until further analysis.

\subsubsection{Detection of Anti-HBs (HBsAb)}

Briefly, HBsAb was detected in the sera of the HIV positive patients using Immunochromatographic assay (Biotec, UK). The kit was used in accordance with the manufacturer's instructions.

\subsubsection{Determination of Absolute CD4+ Count}

CD4+ counts of patients were determined using the BD FACS count automated CD4 counting analyser following manufacturer's protocol. Whole blood was collected in K3 EDTA vacutainer tube and stored for no longer than 6 hours at room temperature $\left(20-25^{\circ} \mathrm{C}\right)$ in the workstation until they were analysed on the FACS Count instrument. Briefly, $50 \mu \mathrm{l}$ of patients' blood were vortexed for 5 seconds and incubated for 60 to 120 minutes at room temperature in the dark. Within 48 hours of preparation, the samples were analysed on the FACS Count instrument, which recorded the CD4 count in cells $/ \mu$ of blood. 


\subsubsection{Interpretation of Immunologic Status Result}

The CD4+ Count of healthy immune competent and HIV negative persons in Nigeria lie between 547-1327 cells $/ \mathrm{mm}^{3}$. Any CD4+ Count within the range of 200-500 cells $/ \mathrm{mm}^{3}$ suggests that the person is immunocompromised according to [18].

\subsubsection{Ethical considerations}

Permissions were sought and given by both the Lagos State Ministry of Health (LSMH) and Lagos State Health Services Commission (LSHSC) while the ethical approval was obtained from the Research, Ethics, Experimentation and Grant Review Committee of the College of Medicine of the University of Lagos, IdiAraba, Lagos, Nigeria. Only patients who satisfied the study inclusion criteria and gave informed consent were recruited for the study.

\section{RESULTS}

Out of the total 74 HIV positive patients studied, 12 $(16.2 \%)$ were males while $62(83.8 \%)$ were females. The average age of the subjects was 33.12 years (range: 2 to 68). Of the 74 (100\%), 2 patients were positive for anti-HBs, giving an overall prevalence of 2.7 $\%$. The patients' mean CD4+ T-cell count at the time of anti-HBs testing was 477 cells $/ \mathrm{mm}^{3}$ (range: 11 to $1,447)$. The age and sex distribution of the patients is shown in Figure I. There was no seroprevalence of antiHBs among the males, while it was $2.7 \%$ among the females.

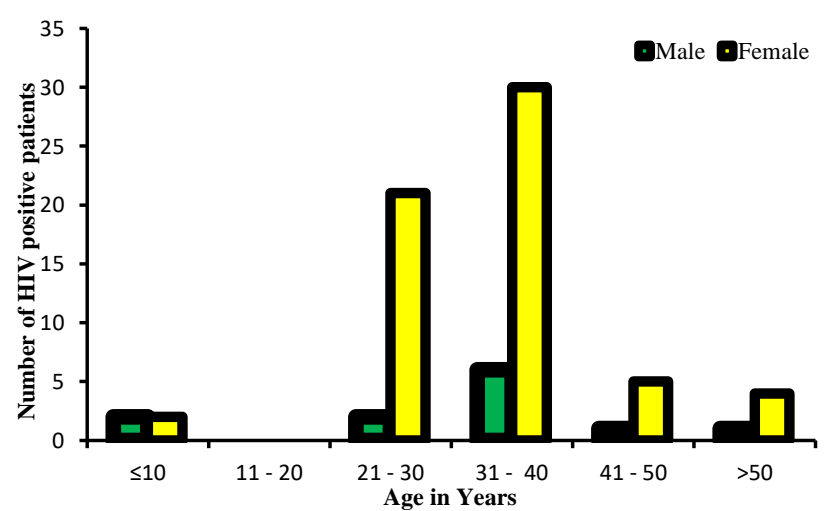

Fig. 1. Age and sex distribution of HIV positive patients.

Age range of 0-10 among the HIV infected patients had the highest mean CD4+ count of 737 while $>50$ had the lowest mean CD4+ count of 333 (Table 1). Seroprevalence of anti-HBs was only recorded in HIV positive patients in the 21-30 years age group (Table I).
Table 1. Mean CD4+ count of HIV patients screened for anti-HBs in Ojo PHC

\begin{tabular}{llll}
\hline $\begin{array}{l}\text { Age } \\
\text { (years) }\end{array}$ & $\begin{array}{l}\text { No. of patients } \\
\text { screened } \\
(\mathbf{n = 5 8 )}\end{array}$ & $\begin{array}{l}\text { Anti-HBs } \\
\text { positive }\end{array}$ & $\begin{array}{l}\text { Mean } \\
\text { CD4+ } \\
\text { Value }\end{array}$ \\
\hline $\mathbf{0 - 1 0}$ & 4 & 0 & 737 \\
\hline $\mathbf{1 1 - 2 0}$ & 0 & 0 & 0 \\
\hline $\mathbf{2 1 - 3 0}$ & 18 & 2 & 607 \\
\hline $\mathbf{3 1 - 4 0}$ & 30 & 0 & 385 \\
\hline $\mathbf{4 1 - 5 0}$ & 4 & 0 & 393 \\
\hline$>\mathbf{5 0}$ & 2 & 0 & 333 \\
\hline
\end{tabular}

Out of the 58 HIV positive patients that had their CD4+ count determined, 9 patients had CD4+ count less than 200 cells $/ \mu \mathrm{l} ; 29$ patients between 200 cells $/ \mu$ land 500 cells $/ \mu$ l while 20 patients greater than 500 cells $/ \mu$ l (Table II). This study revealed prevalence of anti-HBs among HIV patients with CD4+ Count ranging from 601-700 and $901-1000$ to be $1.7 \%$ respectively (Table II).

Table II: Immunologic characteristics of HIV patients screened for anti-HBs

\begin{tabular}{lll}
\hline $\begin{array}{l}\text { CD4 Count } \\
\text { Range } \\
\left(\text { Cells } / \mathbf{m m}^{3}\right)\end{array}$ & $\begin{array}{l}\text { No. of Subjects } \\
\text { Examined }\end{array}$ & $\begin{array}{l}\text { Anti-HBs } \\
\text { Positive (\%) }\end{array}$ \\
\hline $0-100$ & 2 & $0(0)$ \\
\hline $101-200$ & 7 & $0(0)$ \\
\hline $201-300$ & 9 & $0(0)$ \\
\hline $301-400$ & 7 & $0(0)$ \\
\hline $401-500$ & 13 & $0(0)$ \\
\hline $501-600$ & 4 & $0(0)$ \\
\hline $601-700$ & 4 & $1(1.7)$ \\
\hline $701-800$ & 2 & $0(0)$ \\
\hline $801-900$ & 6 & $0(0)$ \\
\hline $901-1000$ & 1 & $1(1.7)$ \\
\hline $1001-1100$ & 1 & $0(0)$ \\
\hline $1101-1200$ & 0 & $0(0)$ \\
\hline $1201-1300$ & 1 & $0(0)$ \\
\hline $1301-1400$ & 0 & $0(0)$ \\
\hline $1401-1500$ & 1 & $0(0)$ \\
\hline Total & $58^{*}$ & $2(3.45)$ \\
\hline
\end{tabular}

$*=$ only 58 out of the total subjects had their CD $4+$ counts determined.

Based on the treatment status of the HIV patients, 31 $(53.4 \%)$ were ART patients while $27(46.6 \%)$ were Non-ART patients (Table III). Protection of $3.5 \%$ was reported among ART naïve patients and $0 \%$ protection among ART patients (Table III). 
Table III: Treatment characteristics of HIV patients screened for anti-HBs

\begin{tabular}{lllll}
\hline Characteristic & Sex & $\begin{array}{l}\text { No. } \\
\text { Tested } \\
(\%)\end{array}$ & $\begin{array}{l}\text { Anti- } \\
\text { HBs } \\
\text { Positive } \\
(\%)\end{array}$ \\
\cline { 2 - 5 } Male & Female & & $\begin{array}{l}31 \\
(53.4)\end{array}$ & $0(0)$ \\
\hline Non-ART & 4 & 26 & $\begin{array}{l}27 \\
(46.6)\end{array}$ & $2(3.45)$ \\
\hline Total & 9 & 49 & $\begin{array}{l}58 \\
(100)\end{array}$ & $2(3.45)$ \\
\hline
\end{tabular}

$\mathrm{n}=58$

${ }^{*} \mathrm{ART}=$ Patients on Antiretroviral Therapy; $\mathrm{n}=$ Number of respondents; \% =Percentage.

\section{DISCUSSION}

The burden of Hepatitis B virus co-infection in HIVpositive individuals continue to take a toll on the health of individuals especially in poor communities in Africa including Nigeria. This co-infection often accelerates progression and complication of HBV, which can result in the loss of previously developed antibody leading to development of acute hepatitis B infection in HIV patients.

In this study, seroprevalence rate of $2.7 \%$ was observed which falls within the documented range of 0.5 $\%$ to $46.8 \%$ reported by previous workers $[1,10,19]$. According to a meta-analysis done by [9], the prevalence of HBV infection in Nigeria ranged from 0.5 $\%$ to $46.8 \%$ while the pooled prevalence estimate for Nigeria was $13.6 \%$. Contrary to the finding in this study, a lower prevalence rate of $1.13 \%$ was reported in Mali [20]; $2.6 \%$ for South Africa [21]; $2.6 \%$ for Ethiopia [22] and $2.3 \%$ for Southern Brazil [17]. In India, however, a higher prevalence rate of $4.9 \%$ was documented [23]. The difference in prevalence in these studies could be attributed to a lot of factors including the differences in geographical locations and population selection.

Demographic data shows that $62(83.8 \%)$ subjects were females while $12(16.2 \%)$ were males. This observation corroborates that of [14] who earlier reported that more females than males visit hospitals for medical attention in Nigeria. This gender inequality is consistent with the sex distribution reported in the treatment center. This is possibly because women present for care after positive HIV test on their sick children, death of their husband, or perhaps they are more sensitive to changes in their health and may be socially conditioned to seek and receive assistance for their sickness. However, this does not necessarily translate to more women being infected with HIV in the population as it has been previously reported by [24] that more men are infected by HIV/AIDS than women. Nine (9) HIV positive patients had CD4 count of less than 200 cells $/ \mu$ which is suggestive that they are immuno-deficient; 29 patients had CD4 count of between $200 \mathrm{cells} / \mu \mathrm{l}$ and $500 \mathrm{cells} / \mu \mathrm{l}$ which indicate that they are immuno-compromised and 20 patients had CD4 count of greater than 500 cells $/ \mu$ indicating immuno-competence (Table II). Prevalence of anti-HBs was only reported in HIV positive patients with CD4 count greater than 500 cells/ $\mu$ l. Although HBsAg was not tested for, however, the low CD4 count $(<500$ cells $/ \mu \mathrm{l})$ reported in anti-HBs negative patients may be as a result of the presence of active infection caused by HBV since the hepatitis B virus has been shown to slightly lower the CD4 count of HIV seropositive patients in other studies [25, 26]. The mean CD4 count in HIV patient in this study was calculated to be 476.3 cells $/ \mu$ l of blood, and those with both HIV and HBV were 792 cells $/ \mu l$. This count is higher than the 230 cells/ $\mu$ l obtained in a study by [24]. It is suggestive of the need for HBV vaccination in the HIV patients. This is to maximize the effectiveness of the vaccine which also should be provided early (before the CD4 cell count declines to $<350$ cells/ul); however, for persons with advanced immunosuppression, vaccination should also not be delayed while awaiting an increase in the CD4 cell count following antiretroviral therapy [27].

Antibody protection of $3.5 \%$ was reported only among ART naïve patients. However, screening for HBV among HIV positive patients is recommended to be performed before the initiation of ART to prevent possible HAART related hepatotoxicity.

Part of the limitations of this study is that the patients were not screened for Hepatitis B viral load owing to limited resources. Also, a nucleic acid-based technique such as Polymerase Chain Reaction (PCR) would have been more helpful in determining the prevalence of hepatitis B exposure and chronic carrier status. Nevertheless, the results obtained in this study are in accordance with other studies and are applicable in improving the care of HIV/AIDS patients.

\section{CONCLUSION}

The low prevalence of $2.7 \%$ anti-HBS in HIV positive patients found in this study may be attributed to the suppression of immune responses in HIV positive patients leading to the loss of previously developed protective antibody against HBV infection. Therefore, anti-HBs screening should be done for all HIV positive patients and those negative should be vaccinated to help them develop protective immunity to HBV infection. The use of other HBV markers such as HBsAg, anti$\mathrm{HBc}, \mathrm{HBeAg}$, and anti-HBe is advocated for future studies. Further investigations at immunological and molecular levels are recommended to elucidate the interaction of HBV and HIV coinfection. Most importantly, better public health enlightenment in health seeking behavior, safe sex practice and overall health promotion should be accentuated to reduce hepatitis $B$ viral burden.

\section{ACKNOWLEDGEMENTS}

We appreciate all the patients who volunteered to be part of this study. The Management and Staff of the different health centres where the patients were recruited, and the Lagos State Ministry of Health, Alausa, Ikeja are hereby acknowledged for their 
supports. The abstract for this study was presented at The World Academy of Sciences, TWAS-ROSSA and the Nigerian Young Academy (NYA) Young Scientists' Conference held in Sheraton, Lagos under Research Presentation PP15, August 23 $3^{\text {rd }}-24^{\text {th }}, 2016$.

\section{COMPETING INTERESTS}

Authors have declared that no competing interest exist.

\section{AUTHORS' CONTRIBUTIONS}

AAA designed the study, carried out laboratory analyses and contributed to manuscript draft. LML managed the literature searches, performed statistical analysis, and wrote the first draft of the manuscript. $\mathrm{AOB}$ contributed to the project design. $\mathrm{AOB}$ and $\mathrm{KOA}$ contributed to data analyses and edited the manuscript. All authors read and approved the final manuscript.

\section{CONSENT}

All authors declare that written informed consent was obtained from the patients.

\section{ETHICAL APPROVAL}

All authors hereby declare that all experiments have been examined and approved by the appropriate ethics committee and have therefore been performed in accordance with the ethical standards laid down in the 1964 Declaration of Helsinki."

\section{REFERENCES}

1. Adegbesan-Omilabu, M., et al., Seroprevalence of hepatitis $B$ virus infection among pregnant women at the antenatal booking clinic of a Tertiary Hospital in Lagos Nigeria. Nigerian journal of clinical practice, 2015. 18(6): p. 819-823.

2. Williams, R., Global challenges in liver disease. Hepatology, 2006. 44(3): p. 521-526.

3. Brooks, G.F.C., K. C.; Butel, J. S.; Morse, S. A.; , Medical microbiology, in Jawetz; Melnick and Adelberg. 2007, McGraw Hill Publishers: New York. p. 425-443.

4. Lavanchy, D., Hepatitis B virus epidemiology, disease burden, treatment, and current and emerging prevention and control measures. Journal of viral hepatitis, 2004. 11(2): p. 97-107.

5. WHO. Hepatitis. 2017 April, 2017 [cited 2017 1st May]; Available from: http://www.who.int/mediacentre/factsheets/fs204/en/.

6. Gitlin, N., Hepatitis B: diagnosis, prevention, and treatment. Clinical Chemistry, 1997. 43(8): p. 15001506.

7. Lok, A.S. and B.J. McMahon, Chronic hepatitis B. Hepatology, 2007. 45(2): p. 507-539.
8. Sadoh, A. and W. Sadoh, Serological markers of hepatitis $B$ infection in infants presenting for their first immunization. Nigerian Journal of Paediatrics, 2013. 40(3): p. 248-253.

9. Musa, B., et al., Prevalence of hepatitis $B$ virus infection in Nigeria, 2000-2013: a systematic review and meta-analysis. Nigerian Journal of clinical practice, 2015. 18(2): p. 163-172.

10. Gyar, S., P. Agbo, and C. Reuben, Assessment of Hepatitis B Co-infection among HIVIAIDS Patients Attending Antiretroviral Therapy (ART) Clinic in Garaku, Central Nigeria. Research Journal of Microbiology, 2014. 9(5): p. 232.

11. Adewole, O.O., et al., Hepatitis $B$ and $C$ virus co-infection in Nigerian patients with HIV infection. The Journal of Infection in Developing Countries, 2009. 3(05): p. 369-375.

12. Thio, C.L., Hepatitis $B$ and human immunodeficiency virus coinfection. Hepatology, 2009. 49(5 Suppl): p. S138-45.

13. Puoti, M., et al., Hepatitis B virus co-infection in human immunodeficiency virus-infected subjects. AIDS rev, 2002. 4(1): p. 27-35.

14. Uneke, C., et al., Prevalence of hepatitis- $B$ surface antigen among blood donors and human immunodeficiency virus-infected patients in Jos, Nigeria. Memórias do Instituto Oswaldo Cruz, 2005. 100(1): p. 13-16.

15. Lesi, O., M. Kehinde, and S. Omilabu, Prevalence of the hepatitis $B$ " $e$ " antigen in Nigerian patients with chronic liver disease. Nigerian Quarterly Journal of Hospital Medicine, 2004. 14(1): p. 1-4.

16. Hamza, M., et al., Prevalence of hepatitis $B$ and $C$ virus infections among HIV-infected patients in a tertiary hospital in North-Western Nigeria. Nigerian Journal of Basic and Clinical Sciences, 2013. 10(2): p. 76.

17. Martins, S., et al., The prevalence of hepatitis $B$ virus infection markers and socio-demographic risk factors in HIV-infected patients in Southern Brazil. Revista da Sociedade Brasileira de Medicina Tropical, 2014. 47(5): p. 552-558.

18. Lar, P., et al., Prevalence and immune status of HIV/HBV co-infected pregnant women. African Journal of Clinical and Experimental Microbiology, 2013. 14(3): p. 120-126.

19. Oladele, O.O., et al., Seroprevalence of Hepatitis $B$ Surface Antigen and Antibody among Pregnant Women Attending a Tertiary Health Institution in Southwestern Nigeria. Religion, 2014. 42: p. 30.

20. Tounkara, A., et al., Seroprevalence of HIV/HBV coinfection in Malian blood donors. Journal of 
the International Association of Physicians in AIDS Care (JIAPAC), 2009. 8(1): p. 47-51.

21. Firhaber, C., et al., The prevalence of hepatitis $B$ co infection in a South African (SA) urban government HIV clinic. South African Medical Journal, 2008. 98(7): p. 541-544.

22. Bezabeh, Y.H., et al., Higher prevalence of Hepatitis $B$ virus Infection among $A R V$-exposed than naive HIV-infected individuals in North Shewa Zone, Ethiopia. Journal of AIDS and HIV Research, 2015. 7(1): p. 10-17.

23. Ahuja, S., et al., Seroprevalence of Hepatitis $B$ and $C$ Co infection in HIV Positive Patients from a Tertiary Care Hospital. JIMSA, 2013. 26: p. 91.
24. Otegbayo, J.A., et al., Prevalence of hepatitis $B$ and $C$ seropositivity in a Nigerian cohort of HIV-infected patients. Ann Hepatol, 2008. 7(2): p. 152-6.

25. Idoko, J., et al., Impact of hepatitis $B$ virus infection on human immunodeficiency virus response to antiretroviral therapy in Nigeria. Clinical infectious diseases, 2009. 49(8): p. 1268-1273.

26. Adesina, O., et al., Human immuno-deficiency virus and hepatitis $B$ virus coinfection in pregnancy at the University College Hospital, Ibadan. African journal of medicine and medical sciences, 2010. 39(4): p. 305310.

27. Aliyu, B., B. Manga, and M. Isa, Prevalence of Hepatitis B Virus Among HIV Positive Patients Attending Specialist Hospital Sokoto, Nigeria. International Journal of Environment, 2013. 2(1): p. 3744. 